\title{
Nickel(II) and copper(II) complexes of 2-(2-pyridyl) benzimidazole: synthesis and structural characterization
}

\author{
Muhammad Altaf · Helen Stoeckli-Evans
}

Received: 9 March 2009/Accepted: 3 June 2009/Published online: 25 June 2009

(C) Springer Science+Business Media B.V. 2009

\begin{abstract}
Pyridyl)benzimidazole (PBI) was synthesized by solvent-free aldol condensation and complexed with nickel(II) and copper(II) nitrate and perchlorate salts by simple reactions at room temperature. The transition metal complexes $\left[\mathrm{Ni}(\mathrm{PBI})_{2} \mathrm{NO}_{3}\right]\left(\mathrm{NO}_{3}\right)(\mathbf{1}),\left[\mathrm{Ni}(\mathrm{PBI})_{3}\right]-$ $\left(\mathrm{ClO}_{4}\right)_{2} \cdot 1.5 \mathrm{H}_{2} \mathrm{O}(2),\left[\mathrm{Cu}(\mathrm{PBI})_{2} \mathrm{NO}_{3}\right]\left(\mathrm{NO}_{3}\right)(3)$, and $\left[\mathrm{Cu}(\mathrm{PBI})_{3}\right]-$ $\left(\mathrm{ClO}_{4}\right)_{2} \cdot 3 \mathrm{H}_{2} \mathrm{O}(4)(\mathrm{PBI}=2$-(2-pyridyl)benzimidazole) were synthesized in good yield and structurally characterized by $\mathrm{X}$-ray crystallography, infrared absorption spectroscopy, and elemental analysis. Complexes $\mathbf{1}$ and $\mathbf{3}$ are isostructural, crystallizing in the same space group $\mathrm{P} 2{ }_{1} / \mathrm{c}$. Both the nickel(II) and copper(II) atoms have distorted square pyramidal geometries. The metal centers in these complexes are coordinated by two molecules of the bidentate ligand (PBI) and an $\mathrm{O}$-atom of the coordinated nitrate anion. Complexes $\mathbf{2}$ and $\mathbf{4}$ are also isostructural but do not crystallize in the same space group: P-1 for $\mathbf{2}$ and Pccn for 4. The geometry around both the nickel(II) and the copper(II) centers is distorted octahedral. Here, the metal atoms are coordinated by three molecules of 2-(2-pyridyl)benzimidazole. The copper(II) complex $\mathbf{4}$ has 2-fold symmetry with one of the three PBI ligands being positionally disordered about the 2-fold axis. Intermolecular $\mathrm{N}-\mathrm{H} \cdots \mathrm{O}$ hydrogen bonds, involving the $\mathrm{NH} \mathrm{H}$-atom and an $\mathrm{O}$-atom of the coordinated nitrate anion, are observed in all four complexes. In $\mathbf{1}$ and $\mathbf{3}$, this gives rise to the formation of centrosymmetric dimer-like structures that are decorated by hydrogen-bonded
\end{abstract}

Electronic supplementary material The online version of this article (doi:10.1007/s11243-009-9238-4) contains supplementary material, which is available to authorized users.

M. Altaf $(\bowtie) \cdot$ H. Stoeckli-Evans

Institute of Physics, University of Neuchâtel,

Rue Emile-Argand 11, 2009 Neuchâtel, Switzerland

e-mail: muhammad.altaf@unine.ch nitrate anions. In $\mathbf{2}$ and $\mathbf{4}$ the perchlorate anions and the water molecules of crystallization are involved in $\mathrm{N}-\mathrm{H} \cdots \mathrm{O}$ and $\mathrm{O}-\mathrm{H} \cdots \mathrm{O}$ hydrogen bonds bridging two symmetry-related cations, thus forming cyclic arrangements. In the case of complex 4, this leads to the formation of two-dimensional hydrogen-bonded networks parallel to plane (011).

\section{Introduction}

The $N, N^{\prime}$-diamine chelating ligand 2-(2-pyridyl)benzimidazole (PBI) has been reported on as early as 1932 [1]. Numerous complexes involving d-block metals and imidazole derivatives are known [2-8], and there is enormous interest in the transition metal complexes of imidazole and its derivatives as ligands [4, 9-13]. Surprisingly, the crystal structure of PBI was only recently reported [14].

Exploring the possibility of synthesizing Schiff bases and other ligands by solid-state condensation reactions [15], we attempted to synthesize 2-(2-pyridyl)benzimidazole by solvent-free aldol condensation, using benzene 1,2-diamine and picolinaldehyde (Scheme 1).

A large number of Schiff bases and their complexes have been studied because of their interesting and important properties, such as catalytic activity, transfer of amino groups, photochromic properties, and their ability to form complexes with transition metal ions [16-20]. Imidazoles and transition metal complexes of imidazoles are also known to display therapeutic activity [21]. Knowledge of the exact structure of these complexes may help to clarify their biological, physical, and chemical properties and help elucidate the mechanisms of their therapeutic action.

In the recent decades, a great deal of interest has been aroused in using coordination polymeric networks, 
Scheme 1 Synthesis of 2-(2-pyridyl)benzimidazole (PBI) by solvent-free aldol condensation

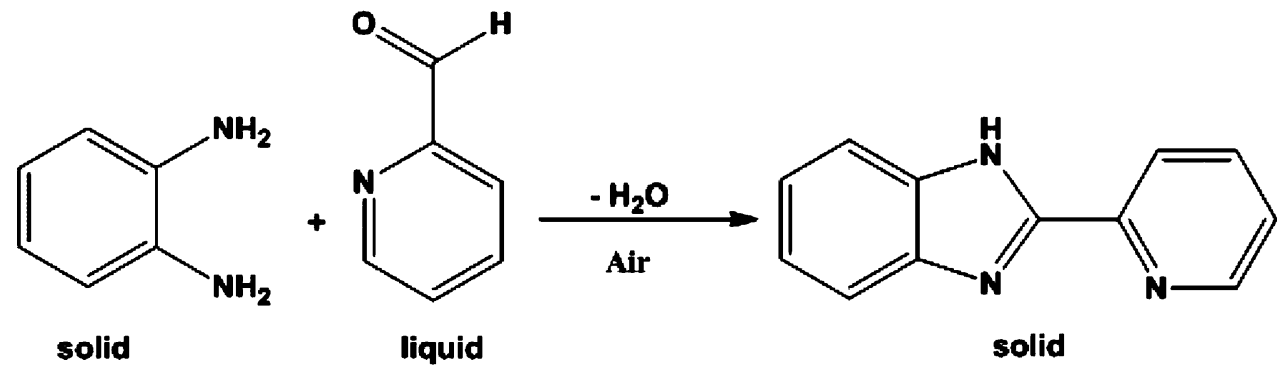

containing transition metal centers with intermolecular interactions, as the basis for attempts to design solid-state structures with preassigned properties [22-24]. Research efforts have been centered on copper(II) and nickel(II) complexes based on $\mathrm{N}$ - and $\mathrm{O}$-donor ligands because of their biological and other potential applications in the life sciences. The bioinorganic chemistry of copper(II) and nickel(II) has become increasingly important, and nickel(II) has been shown to lie at the active site of several important classes of metalloenzymes including, most notably, nickel(II) hydrogenases. Copper salts and their complexes are also well known for their antifungal and antibacterial properties [25-27]. Extensive research efforts have been centered on $\mathrm{N}, \mathrm{N}^{\prime}$-donor ligand metal complexes, showing luminescence from charge-transfer excited states. The luminescence properties of such complexes have resulted in the study of many bidentate diimine-type ligands and their transition metal complexes that show analogous behavior [28]. The opportunities for tuning the steric and electronic properties of luminescent metal centers using such 'bipyridine analogues' are a topic of current research [2]. Phosphorescent transition metal complexes also have a wide range of potential applications, such as photochemical catalysis, chemical sensors, and sensitizers in photovoltaic devices, and as emitters in organic light-emitting diodes [28-32].

Here, we report on the synthesis and the crystallographic, spectroscopic, and elemental analyses of two new nickel(II) and two new copper(II) complexes of 2-(2pyridyl)benzimidazole (PBI).

\section{Experimental}

All metal salts and solvents were commercial products of analytical grade and were used without further purification. Microanalyses were carried out by Mr. D. Mooser (Department of Chemistry, University of Applied Sciences, Fribourg, Switzerland). The IR spectra were recorded as $\mathrm{KBr}$ pellets on a Perkin Elmer Spectrum One FT-IR instrument.

Warning: Perchlorate salts are dangerous to handle, and only small quantities should be used. We did not encounter any difficulties during the work. 2-(2-pyridyl)benzimidazole (PBI)

The ligand was synthesized by a solvent-free aldol condensation (Scheme 1) [15]. Equimolar amounts of benzene-1,2-diamine and picolinaldehyde were ground together giving a viscous liquid, which solidified with time. The yield was quantitative, and the material was identified as 2-(2-pyridyl)benzimidazole with reference to its spectral data [33].

\section{$\left[\mathrm{Ni}(\mathrm{PBI})_{2} \mathrm{NO}_{3}\right]\left(\mathrm{NO}_{3}\right)(\mathbf{1})$}

A solution of $0.2 \mathrm{mmol}$ ( $40 \mathrm{mg}$ ) of 2-(2-pyridyl)benzimidazole (PBI) in $10 \mathrm{~mL}$ of $\mathrm{MeOH} / \mathrm{MeCN}$ (1:1) was added to $0.1 \mathrm{mmol}(29 \mathrm{mg})$ of $\mathrm{Ni}\left(\mathrm{NO}_{3}\right)_{2} \cdot 6 \mathrm{H}_{2} \mathrm{O}$ in $15 \mathrm{~mL}$ distilled water, and the resulting solution was heated moderately for $20 \mathrm{~min}$. The clear green solution obtained was allowed to cool slowly to room temperature and then filtered to avoid any impurities. Slow evaporation of the solvent at room temperature gave deep green crystals. The solid crystalline product was filtered off, washed with icecold $10 \mathrm{~mL}$ distilled water, and air-dried. Yield $78.8 \%$. Elemental analysis: $\mathrm{C}_{24} \mathrm{H}_{18} \mathrm{~N}_{8} \mathrm{NiO}_{6}$ calcd: $\mathrm{C}, 50.2 ; \mathrm{H}, 3.1$; $\mathrm{N}, 19.5 \%$. Found: $\mathrm{C}, 50.8 ; \mathrm{H}, 3.7 ; \mathrm{N}, 19.0 \%$. IR ( $\mathrm{KBr}$ pellets, $\left.v, \mathrm{~cm}^{-1}\right): 3,513(\mathrm{~m}), 3,233(\mathrm{~m}), 3,063(\mathrm{w}), 1,611(\mathrm{~m})$, 1,603(vs), 1,494(m), 1,484(vs), 1,384(vs), 1,151(s), 1,059(m), 908(s), 816(m), 744(vs), 631(m), and 576(m).

\section{$\left[\mathrm{Ni}(\mathrm{PBI})_{3}\right]\left(\mathrm{ClO}_{4}\right)_{2} \cdot 1.25 \mathrm{H}_{2} \mathrm{O}(\mathbf{2})$}

A solution of $0.3 \mathrm{mmol}(59 \mathrm{mg})$ of 2-(2-pyridyl)benzimidazole (PBI) in $10 \mathrm{~mL}$ of $\mathrm{MeOH} / \mathrm{MeCN}$ (1:1) was added to $0.1 \mathrm{mmol}(37 \mathrm{mg})$ of $\mathrm{Ni}\left(\mathrm{ClO}_{4}\right)_{2} \cdot 6 \mathrm{H}_{2} \mathrm{O}$ in $10 \mathrm{~mL}$ distilled water. The reaction mixture was mechanically stirred for $20 \mathrm{~min}$ at room temperature. The light brown solution obtained was filtered to avoid any impurities, and the filtrate was allowed to evaporate slowly. After 2 days, brown plate-like crystals were obtained. The solid crystalline product was collected, washed with ice-cold distilled water $(10 \mathrm{~mL})$, and air-dried Yield $62.9 \%$. Elemental analysis: $\mathrm{C}_{36} \mathrm{H}_{29.50} \mathrm{Cl}_{2} \mathrm{~N}_{9} \mathrm{NiO}_{9.25}$ calcd: $\mathrm{C}, 50.0 ; \mathrm{H}, 3.4 ; \mathrm{N}$, 14.6\%. Found: C, 49.4; H, 3.4; N, 14.5\%. IR (KBr pellets, $\left.v, \mathrm{~cm}^{-1}\right): 3,605(\mathrm{~b}), 3,452(\mathrm{~s}), 3,257(\mathrm{~m}), 3,025(\mathrm{w}), 1,615(\mathrm{~s})$, 
1,605(vs), 1,478(m), 1,463(vs), 1,362(vs), 1,141(s), 1,020(m), 978(s), 802(m), 715(vs), 605(m), and 522(m).

\section{$\left[\mathrm{Cu}(\mathrm{PBI})_{2} \mathrm{NO}_{3}\right]\left(\mathrm{NO}_{3}\right)(3)$}

A solution of $0.2 \mathrm{mmol}$ ( $40 \mathrm{mg}$ ) of 2-(2-pyridyl)benzimidazole (PBI) in $10 \mathrm{~mL}$ of $\mathrm{MeOH} / \mathrm{MeCN}$ (1:1) was mixed vigorously with $0.1 \mathrm{mmol}(24 \mathrm{mg})$ of $\mathrm{Cu}\left(\mathrm{NO}_{3}\right)_{2} \cdot 3 \mathrm{H}_{2} \mathrm{O}$ in $10 \mathrm{~mL}$ distilled water. The reaction mixture was heated moderately with continuous stirring for $15 \mathrm{~min}$. The transparent green solution was kept undisturbed for slow evaporation at room temperature. After 3 days, green block-like crystals were obtained. The solid crystalline product was collected by filtration and air-dried. Yield 73.9\%. Elemental analysis: $\mathrm{C}_{24} \mathrm{H}_{18} \mathrm{~N}_{8} \mathrm{CuO}_{6}$ calcd: $\mathrm{C}, 49.8 ; \mathrm{H}, 3.1 ; \mathrm{N}, 19.4 \%$. Found: C, 49.5; H, 3.1; N, 18.9\%. IR (KBr pellets, $\left.v, \mathrm{~cm}^{-1}\right)$ : 3,433(s), 3,253(m), 3,043(w), 1,617(m), 1,603(v)s, 1,498(m), 1,473(v)s, 1,398(v)s, 1,165(s), 1,045(m), 951(s), 807(m), 764(vs), 625(m), and 563(m).

$$
\left[\mathrm{Cu}(\mathrm{PBI})_{3}\right]\left(\mathrm{ClO}_{4}\right)_{2} \cdot 3 \mathrm{H}_{2} \mathrm{O}(4)
$$

A solution of $0.3 \mathrm{mmol}(59 \mathrm{mg})$ of 2-(2-pyridyl)benzimidazole (PBI) in $10 \mathrm{~mL}$ of $\mathrm{MeOH} / \mathrm{MeCN}$ (1:1) was added to $0.1 \mathrm{mmol}(37 \mathrm{mg})$ of $\mathrm{Cu}\left(\mathrm{ClO}_{4}\right)_{2} \cdot 6 \mathrm{H}_{2} \mathrm{O}$ in $10 \mathrm{~mL}$ distilled water. The solution was heated at $25{ }^{\circ} \mathrm{C}$ with continuous stirring for $20 \mathrm{~min}$. Deep green solution obtained was filtered to avoid any impurities and kept undisturbed to evaporate slowly for crystallization. After 3 days, green plate-like crystals were obtained. The green crystalline product was filtered off, washed with small amount of distilled water, and air-dried. Yield $68.3 \%$. Elemental analysis: $\mathrm{C}_{36} \mathrm{H}_{33} \mathrm{Cl}_{2}$ $\mathrm{CuN}_{9} \mathrm{O}_{11}$ calcd: $\mathrm{C}, 47.9 ; \mathrm{H}, 3.7 ; \mathrm{N}, 13.6 \%$. Found: $\mathrm{C}, 47.9 ; \mathrm{H}$, 3.6; N, 13.9\%. IR (KBr pellets, $\left.v, \mathrm{~cm}^{-1}\right): 3,550(\mathrm{~b}), 3,412(\mathrm{~s})$, 3,233(m), 3,067(w), 1,612(s), 1,607(vs), 1,488(m), 1,472(vs), 1,377(vs), 1,143(s), 1,030(m), 972(s), 801(m), 734(vs), 615(m), and 533(m).

\section{Crystal structure analysis}

The intensity data were collected at $173 \mathrm{~K}$ on either a onecircle ( $\phi$ scans) [34] or a two-circle ( $\omega$ and $\phi$ scans) [35] Stoe Image Plate Diffraction System, using MoK $\alpha$ graphite monochromated radiation. The structures were solved by direct methods using the program SHELXS-97 [36]. The refinement and all further calculations were carried out using SHELXL-97 [36]. In 1, 2, and 3, the NH H-atoms were included in calculated positions and treated as riding atoms. It was not possible to locate the water $\mathrm{H}$-atoms in $\mathbf{2}$. The $\mathbf{N H}$ and water $\mathrm{H}$-atoms in $\mathbf{4}$ were located from Fourier difference maps and freely refined or refined with distance restraints. The $\mathrm{C}$-bound $\mathrm{H}$-atoms in all four complexes were included in calculated positions and treated as riding atoms using SHELXL default parameters. The non-H atoms were refined anisotropically, using weighted, fullmatrix, least-squares on $F^{2}$. Multiscan absorption corrections [37] were applied using the MULscanABS routine in PLATON [38]. In complexes 2 and $\mathbf{4}$, one of the perchlorate anions is disordered. In complex $\mathbf{4}$, the cation possesses 2-fold symmetry, and one of the BPI ligands is positionally disordered about the 2 -fold axis. A summary of crystal data and refinement details for compounds 1-4 are given in Table 1, and selected bond lengths and angles are listed in Table 2. Details of the hydrogen bonding are given in Table 3.

\section{Results and discussions}

Crystal structure of $\left[\mathrm{Ni}(\mathrm{PBI})_{2} \mathrm{NO}_{3}\right]\left(\mathrm{NO}_{3}\right)(\mathbf{1})$

The coordination environment around the nickel(II) ion in $\mathbf{1}$ is distorted square pyramidal with four $\mathrm{N}$-donor atoms of two chelating PBI ligands and an O-atom of the coordinated counter nitrate ion (Fig. 1a). The second anion is not coordinated to the metal center. The degree of trigonality, as defined by the $\tau$ factor, is 0.16 ( $\tau=0$ for square pyramidal and 1 for trigonal bipyramidal) [39]. The axial position is occupied by a $\mathrm{N}$-atom of a pyridyl ring, and the four equatorial positions are occupied by three $\mathrm{N}$-donor atoms of two $\mathrm{PBI}$ ligands and an $\mathrm{O}$-atom of the coordinated nitrate anion. In this $\mathrm{NiN}_{4} \mathrm{O}$ coordination sphere, the $\mathrm{Ni}-\mathrm{N}$ bond distances range from $1.955(6)$ to $2.230(6) \AA$. There is distinct difference between the two Ni-Npyridyl bond lengths (2.230(6) and 2.064(5) $\AA$ ) and the Ni-Nimidazole bond lengths $(1.955(6)$ and $1.980(6) \AA)$, indicating that the imidazole nitrogen is a much stronger donor than the pyridyl $\mathrm{N}$-atom. There is also a considerable difference between the individual Ni-Npyridyl bond lengths (Table 2). This difference is attributed to the geometrical positions of the pyridyl rings around the metal center; it is well known that equatorial bond distances are shorter than axial bond distances. The $\mathrm{Ni}-\mathrm{O}$ bond length of 2.061(6) $\AA$ is in the normal range. The associated $\mathrm{N}-\mathrm{Ni}-\mathrm{N}$ bond angles, ranging from $78.8(2)$ to $177.5(2)^{\circ}$, and the $\mathrm{N}-\mathrm{Ni}-\mathrm{O}$ bond angles, ranging from $87.5(2)$ to $167.7(2)^{\circ}$, describe the distorted square pyramidal geometry around the nickel(II) metal center. The pyridyl and benzimidazole mean planes of the PBI ligands are not coplanar, with dihedral angles of 7.6(3) and 9.0(3) . The distortions are believed to be due to the presence of intermolecular $\mathrm{N}-\mathrm{H} \cdots \mathrm{O}$ hydrogen bonds involving the imidazole $\mathrm{NH} \mathrm{H}$-atoms and $\mathrm{O}$-atoms of the coordinated and non-coordinated nitrate anions (Table 3). In the crystal, this leads to the formation of centrosymmetric dimer-like structures decorated by $\mathrm{NO}_{3}{ }^{-}$anions (Fig. 1b). 
Table 1 Summary of crystal data and structure refinement parameters for complexes 1-4

\begin{tabular}{|c|c|c|c|c|}
\hline Complex & 1 & 2 & 3 & 4 \\
\hline Empirical formula & $\mathrm{C}_{24} \mathrm{H}_{18} \mathrm{~N}_{8} \mathrm{NiO}_{6}$ & $\mathrm{C}_{36} \mathrm{H}_{29.50} \mathrm{Cl}_{2} \mathrm{~N}_{9} \mathrm{NiO}_{9.25}$ & $\mathrm{C}_{24} \mathrm{H}_{18} \mathrm{CuN}_{8} \mathrm{O}_{6}$ & $\mathrm{C}_{36} \mathrm{H}_{33} \mathrm{Cl}_{2} \mathrm{CuN}_{9} \mathrm{O}_{11}$ \\
\hline Formula weight & 573.18 & 865.80 & 578.00 & 902.15 \\
\hline Crystal size (mm) & $0.22 \times 0.04 \times 0.04$ & $0.30 \times 0.27 \times 0.11$ & $0.50 \times 0.40 \times 0.35$ & $0.40 \times 0.40 \times 0.15$ \\
\hline Wavelength $(\AA)$ & 0.71073 & 0.71073 & 0.71073 & 0.71073 \\
\hline Temperature (K) & 173 & 173 & 173 & 173 \\
\hline Crystal symmetry & Monoclinic & Triclinic & Monoclinic & Orthorhombic \\
\hline Space group & P $2{ }_{1} / \mathrm{c}$ (No. 14) & P-1 (No. 2) & P 2 1 c (No. 14) & P ccn (No. 56) \\
\hline$a(\AA)$ & $17.878(2)$ & $11.8783(13)$ & $17.8845(9)$ & $11.8295(7)$ \\
\hline$b(\AA)$ & $7.4827(7)$ & $12.2865(13)$ & $7.4774(3)$ & $14.3716(7)$ \\
\hline$c(\AA)$ & $19.402(2)$ & $14.8233(17)$ & $19.4123(11)$ & 23.1942(18) \\
\hline$\alpha\left({ }^{\circ}\right)$ & 90 & $88.355(13)$ & 90 & 90 \\
\hline$\beta\left({ }^{\circ}\right)$ & $115.212(8)$ & $72.460(13)$ & $115.372(4)$ & 90 \\
\hline$\gamma\left({ }^{\circ}\right)$ & 90 & 72.394(13) & 90 & 90 \\
\hline$V\left(\AA^{3}\right)$ & $2348.3(4)$ & $1961.5(4)$ & $2345.6(2)$ & 3943.2(4) \\
\hline$Z$ & 4 & 2 & 4 & 4 \\
\hline$D_{\mathrm{c}}\left(\mathrm{Mg} \mathrm{m}^{-3}\right)$ & 1.447 & 1.466 & 1.637 & 1.520 \\
\hline$\mu(\mathrm{Mo}-\mathrm{K} \alpha)\left(\mathrm{mm}^{-1}\right)$ & 0.416 & 0.70 & 0.992 & 0.761 \\
\hline$F(000)$ & 1,176 & 864 & 1,180 & 1,852 \\
\hline$\theta$ Limits $\left({ }^{\circ}\right)$ & $1.3-25.2$ & $2-25.9$ & $2.1-29.2$ & $2.2-26.0$ \\
\hline Collected reflections & 14,987 & 15,432 & 37,005 & 20,584 \\
\hline Unique reflections $\left(R_{\text {int }}\right)$ & $4,185(0.151)$ & $7,119(0.096)$ & $6,339(0.041)$ & $3,866(0.117)$ \\
\hline Observed reflections $[I>2 \sigma(I)]$ & 2,139 & 3,317 & 5,324 & 1,740 \\
\hline Goodness of fit on $F^{2}$ & 0.71 & 0.83 & 1.04 & 0.78 \\
\hline$R_{1}(F),[I>2 \sigma(I)]^{\mathrm{a}}$ & 0.0562 & 0.061 & 0.0531 & 0.0506 \\
\hline$w R_{2}\left(F^{2}\right),[I>2 \sigma(I)]^{\mathrm{b}}$ & 0.1586 & 0.174 & 0.1392 & 0.1280 \\
\hline Largest diff. peak, hole $\left(e \AA^{-3}\right)$ & $0.59,-0.28$ & $0.68,-0.79$ & $1.68,-1.05$ & $0.29,-0.68$ \\
\hline
\end{tabular}

${ }^{\mathrm{a}} R_{1}=\sum|| F_{o}|-| F_{c} \| / \sum\left|F_{o}\right|$

${ }^{\mathrm{b}} w R_{2}=\left[\Sigma w\left(F_{o}^{2}-F_{c}^{2}\right)^{2} / \Sigma w F_{o}^{4}\right]^{1 / 2}$

Crystal structure of $\left[\mathrm{Ni}(\mathrm{PBI})_{3}\right]\left(\mathrm{ClO}_{4}\right)_{2} \cdot 1.5 \mathrm{H}_{2} \mathrm{O}(2)$

In complex 2 , the $\mathrm{Ni}^{\mathrm{II}}$ ion is hexa-coordinated by three bidentate chelating PBI ligands, forming a slightly distorted octahedron (Fig. 2a). This compound is isomorphous with the iron(II) complex [4], which has been extensively studied for its spin-crossover properties [40]. The $\mathrm{Ni}-\mathrm{N}$ bond lengths vary from 2.054(5) to 2.134(5) $\AA$, showing again that $\mathrm{N}$-donor atom of the imidazole ring is a strong donor compared to pyridyl N-donor atom (Table 2). The $\mathrm{N}-\mathrm{Ni}-\mathrm{N}$ bond angles range from $78.50(18)$ to $173.37(7)^{\circ}$. The bond distances and bond angles of three PBI ligands are in the normal range. The pyridyl and benzimidazole mean planes of two of the PBI molecules are not coplanar, with dihedral angles of 5.0(2) and $11.5(3)^{\circ}$, the third one has a dihedral angle of only $1.0(2)^{\circ}$. The distortions from planarity are believed to be due to the presence of $\mathrm{N}-\mathrm{H} \cdots \mathrm{O}$ hydrogen bonding contacts involving the water molecules of crystallization and the $\mathrm{O}$-atoms of the perchlorate anions (Table 3). In the crystal, these hydrogen bonds bridge two symmetry-related cations, thus forming cyclic arrangements (Fig. 2b).

Crystal structure of $\left[\mathrm{Cu}(\mathrm{PBI})_{2} \mathrm{NO}_{3}\right]\left(\mathrm{NO}_{3}\right)(3)$

The single crystal structure of complex $\mathbf{3}$ is isostructural and isomorphous to complex $\mathbf{1}$. Both complexes crystallize in the same space group $\mathrm{P} 22_{1} / \mathrm{c}$ with similar unit cell dimensions. A perspective view of the crystal structure of complex 3 is shown in Fig. 3a. The coordination environment around the copper(II) ion in $\mathbf{3}$ is distorted square pyramidal with four $\mathrm{N}$-donor atoms of two chelating PBI ligands and an $\mathrm{O}$-atom of the coordinated counter nitrate ion. The second anion is not coordinated to the metal center. The degree of trigonality, as defined by the factor $\tau$, is 0.17 ( $\tau=0$ for square pyramidal and 1 for trigonal bipyramidal) [39]. The axial position is occupied by a $\mathrm{N}$-atom of a pyridyl ring, and the four equatorial positions are occupied by three $\mathrm{N}$-donor atoms of two PBI ligands and an $\mathrm{O}$-atom of the coordinated nitrate anion. The bond 
Table 2 Selected bond distances $(\AA)$ and bond angles $\left(^{\circ}\right)$ in complexes 1-4

\begin{tabular}{|c|c|c|c|}
\hline \multicolumn{2}{|l|}{ Bond distances $(\AA)$} & \multicolumn{2}{|l|}{ Bond angles $\left({ }^{\circ}\right)$} \\
\hline (1) & & (2) & \\
\hline $\mathrm{Ni}(1)-\mathrm{N}(1)$ & $2.064(5)$ & $\mathrm{Ni}(1)-\mathrm{N}(1)$ & $2.134(5)$ \\
\hline $\mathrm{Ni}(1)-\mathrm{N}(2)$ & $1.955(6)$ & $\mathrm{Ni}(1)-\mathrm{N}(2)$ & $2.054(5)$ \\
\hline $\mathrm{Ni}(1)-\mathrm{N}(4)$ & $2.230(6)$ & $\mathrm{Ni}(1)-\mathrm{N}(4)$ & $2.131(5)$ \\
\hline $\mathrm{Ni}(1)-\mathrm{N}(5)$ & $1.980(6)$ & $\mathrm{Ni}(1)-\mathrm{N}(5)$ & $2.072(4)$ \\
\hline \multirow[t]{2}{*}{$\mathrm{Ni}(1)-\mathrm{O}(1)$} & $2.061(6)$ & $\mathrm{Ni}(1)-\mathrm{N}(7)$ & $2.128(5)$ \\
\hline & & $\mathrm{Ni}(1)-\mathrm{N}(8)$ & $2.070(5)$ \\
\hline $\mathrm{N}(1)-\mathrm{Ni}(1)-\mathrm{N}(4)$ & $102.8(2)$ & $\mathrm{N}(1)-\mathrm{Ni}(1)-\mathrm{N}(2)$ & $78.63(18)$ \\
\hline $\mathrm{N}(2)-\mathrm{Ni}(1)-\mathrm{N}(1)$ & $81.5(2)$ & $\mathrm{N}(1)-\mathrm{Ni}(1)-\mathrm{N}(4)$ & $91.73(19)$ \\
\hline $\mathrm{N}(2)-\mathrm{Ni}(1)-\mathrm{N}(4)$ & $102.2(2)$ & $\mathrm{N}(1)-\mathrm{Ni}(1)-\mathrm{N}(5)$ & $94.20(17)$ \\
\hline $\mathrm{N}(2)-\mathrm{Ni}(1)-\mathrm{N}(5)$ & $177.5(2)$ & $\mathrm{N}(1)-\mathrm{Ni}(1)-\mathrm{N}(7)$ & $173.37(17)$ \\
\hline $\mathrm{N}(5)-\mathrm{Ni}(1)-\mathrm{N}(4)$ & $78.8(2)$ & $\mathrm{N}(1)-\mathrm{Ni}(1)-\mathrm{N}(8)$ & $96.46(18)$ \\
\hline $\mathrm{N}(5)-\mathrm{Ni}(1)-\mathrm{N}(1)$ & $96.0(2)$ & $\mathrm{N}(2)-\mathrm{Ni}(1)-\mathrm{N}(4)$ & $94.25(19)$ \\
\hline $\mathrm{N}(2)-\mathrm{Ni}(1)-\mathrm{O}(1)$ & $94.9(2)$ & $\mathrm{N}(2)-\mathrm{Ni}(1)-\mathrm{N}(5)$ & $169.7(2)$ \\
\hline $\mathrm{N}(1)-\mathrm{Ni}(1)-\mathrm{O}(1)$ & $167.7(2)$ & $\mathrm{N}(2)-\mathrm{Ni}(1)-\mathrm{N}(7)$ & $96.20(18)$ \\
\hline $\mathrm{N}(5)-\mathrm{Ni}(1)-\mathrm{O}(1)$ & $87.5(2)$ & $\mathrm{N}(2)-\mathrm{Ni}(1)-\mathrm{N}(8)$ & $89.47(19)$ \\
\hline \multirow[t]{6}{*}{$\mathrm{O}(1)-\mathrm{Ni}(1)-\mathrm{N}(4)$} & $89.5(2)$ & $\mathrm{N}(4)-\mathrm{Ni}(1)-\mathrm{N}(5)$ & $78.50(18)$ \\
\hline & & $\mathrm{N}(4)-\mathrm{Ni}(1)-\mathrm{N}(7)$ & $92.80(18)$ \\
\hline & & $\mathrm{N}(4)-\mathrm{Ni}(1)-\mathrm{N}(8)$ & $171.53(18)$ \\
\hline & & $\mathrm{N}(5)-\mathrm{Ni}(1)-\mathrm{N}(7)$ & $91.45(17)$ \\
\hline & & $\mathrm{N}(5)-\mathrm{Ni}(1)-\mathrm{N}(8)$ & $98.70(18)$ \\
\hline & & $\mathrm{N}(7)-\mathrm{Ni}(1)-\mathrm{N}(8)$ & $79.23(18)$ \\
\hline (3) & & (4) & \\
\hline $\mathrm{Cu}(1)-\mathrm{N}(1)$ & $2.228(2)$ & $\mathrm{Cu}(1)-\mathrm{N}(1)$ & $2.243(3)$ \\
\hline $\mathrm{Cu}(1)-\mathrm{N}(2)$ & $1.977(2)$ & $\mathrm{Cu}(1)-\mathrm{N}(3)$ & $2.006(3)$ \\
\hline $\mathrm{Cu}(1)-\mathrm{N}(4)$ & $2.056(2)$ & $\mathrm{Cu}(1)-\mathrm{N}(13)$ & $1.867(5)$ \\
\hline $\mathrm{Cu}(1)-\mathrm{N}(5)$ & $1.959(2)$ & $\mathrm{Cu}(1)-\mathrm{N}(22)$ & $2.639(3)$ \\
\hline $\mathrm{Cu}(1)-\mathrm{O}(1)$ & $2.061(2)$ & & \\
\hline $\mathrm{Cu}(1)-\mathrm{O}(2)$ & $2.633(2)$ & & \\
\hline $\mathrm{N}(1)-\mathrm{Cu}(1)-\mathrm{O}(1)$ & $89.41(9)$ & $\mathrm{N}(1)-\mathrm{Cu}(1)-\mathrm{N}(3)$ & $78.10(12)$ \\
\hline $\mathrm{N}(2)-\mathrm{Cu}(1)-\mathrm{O}(1)$ & $87.21(9)$ & $\mathrm{N}(1)-\mathrm{Cu}(1)-\mathrm{N}(13)$ & $155.8(2)$ \\
\hline $\mathrm{N}(4)-\mathrm{Cu}(1)-\mathrm{O}(1)$ & $167.48(9)$ & $\mathrm{N}(1)-\mathrm{Cu}(1)-\mathrm{N}(1)^{\mathrm{i}}$ & $89.04(12)$ \\
\hline $\mathrm{N}(5)-\mathrm{Cu}(1)-\mathrm{O}(1)$ & $94.94(10)$ & $\mathrm{N}(1)-\mathrm{Cu}(1)-\mathrm{N}(3)^{\mathrm{i}}$ & $92.19(12)$ \\
\hline $\mathrm{N}(1)-\mathrm{Cu}(1)-\mathrm{N}(2)$ & $78.65(9)$ & $\mathrm{N}(1)-\mathrm{Cu}(1)-\mathrm{N}(13)^{\mathrm{i}}$ & $114.9(2)$ \\
\hline $\mathrm{N}(1)-\mathrm{Cu}(1)-\mathrm{N}(4)$ & $103.06(9)$ & $\mathrm{N}(1)-\mathrm{Cu}(1)-\mathrm{N}(22)^{\mathrm{i}}$ & $83.94(11)$ \\
\hline $\mathrm{N}(1)-\mathrm{Cu}(1)-\mathrm{N}(5)$ & $102.33(9)$ & $\mathrm{N}(3)-\mathrm{Cu}(1)-\mathrm{N}(13)$ & $96.4(2)$ \\
\hline $\mathrm{N}(2)-\mathrm{Cu}(1)-\mathrm{N}(4)$ & $96.23(10)$ & $\mathrm{N}(3)-\mathrm{Cu}(1)-\mathrm{N}(22)$ & $94.97(11)$ \\
\hline $\mathrm{N}(2)-\mathrm{Cu}(1)-\mathrm{N}(5)$ & 177.63(10) & $\mathrm{N}(3)-\mathrm{Cu}(1)-\mathrm{N}(3)^{\mathrm{i}}$ & $166.48(12)$ \\
\hline \multirow[t]{3}{*}{$\mathrm{N}(4)-\mathrm{Cu}(1)-\mathrm{N}(5)$} & $81.46(10)$ & $\mathrm{N}(3)-\mathrm{Cu}(1)-\mathrm{N}(13)^{\mathrm{i}}$ & $96.2(2)$ \\
\hline & & $\mathrm{N}(3)-\mathrm{Cu}(1)-\mathrm{N}(22)^{\mathrm{i}}$ & $93.36(11)$ \\
\hline & & $\mathrm{N}(13)-\mathrm{Cu}(1)-\mathrm{N}(22)^{\mathrm{i}}$ & $72.79(19)$ \\
\hline
\end{tabular}

Symmetry code: (i) $-x+1 / 2,-y+3 / 2, z$

lengths and angles involving the copper(II) atom follow the same trend as observed for complex 1 (Table 2). As in complexes $\mathbf{1}$ and 2, the PBI ligands are slightly twisted, with the dihedral angles between the benzimidazole mean
Table 3 Summary of hydrogen bonding interactions $\left({ }^{\circ}, \AA\right)$ in complexes $\mathbf{1}$ and $\mathbf{3}$

\begin{tabular}{|c|c|c|c|c|}
\hline $\mathrm{D}-\mathrm{H} \cdots \mathrm{A}$ & D-H & $\mathrm{H} \cdots \mathrm{A}$ & $\mathrm{D} \cdots \mathrm{A}$ & DHA \\
\hline \multicolumn{5}{|l|}{ (1) } \\
\hline $\mathrm{N} 3-\mathrm{H} 3 \mathrm{~N} \cdots \mathrm{O} 5^{\mathrm{i}}$ & 0.88 & 1.86 & $2.708(8)$ & 162 \\
\hline $\mathrm{N} 6-\mathrm{H} 6 \mathrm{~N} \cdots \mathrm{O} 1^{\mathrm{ii}}$ & 0.88 & 2.34 & $2.998(8)$ & 132 \\
\hline $\mathrm{N} 6-\mathrm{H} 6 \mathrm{~N} \cdots \mathrm{O} 3^{\mathrm{ii}}$ & 0.88 & 2.19 & $3.069(8)$ & 171 \\
\hline \multicolumn{5}{|l|}{ (2) } \\
\hline $\mathrm{N} 3-\mathrm{H} 3 \mathrm{~N} \cdots \mathrm{O} 24 \mathrm{~B}^{\mathrm{i}}$ & 0.88 & 2.03 & $2.880(12)$ & 162 \\
\hline $\mathrm{N} 6-\mathrm{H} 6 \mathrm{~N} \cdots \mathrm{O} 2^{\mathrm{ii}}$ & 0.88 & 2.17 & $3.024(7)$ & 165 \\
\hline 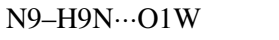 & 0.88 & 1.92 & $2.772(9)$ & 162 \\
\hline \multicolumn{5}{|l|}{ (3) } \\
\hline $\mathrm{N} 3-\mathrm{H} 3 \mathrm{~N} \cdots \mathrm{O} 1^{\mathrm{i}}$ & 0.88 & 2.34 & $3.001(4)$ & 132 \\
\hline $\mathrm{N} 3-\mathrm{H} 3 \mathrm{~N} \cdots \mathrm{O} 3^{\mathrm{i}}$ & 0.88 & 2.21 & $3.084(4)$ & 171 \\
\hline $\mathrm{N} 6-\mathrm{H} 6 \mathrm{~N} \cdots \mathrm{O} 4^{\mathrm{ii}}$ & 0.88 & 1.85 & $2.700(4)$ & 162 \\
\hline \multicolumn{5}{|l|}{ (4) } \\
\hline $\mathrm{O} 1 \mathrm{~W}-\mathrm{H} 1 \mathrm{WA} \cdots \mathrm{O} 1^{\mathrm{ii}}$ & $0.84(5)$ & $2.31(6)$ & $2.960(8)$ & $136(5)$ \\
\hline O1W-H1WA $\cdots$ O4 $\mathrm{B}^{\mathrm{ii}}$ & $0.84(5)$ & $2.26(6)$ & $2.987(10)$ & $146(6)$ \\
\hline $\mathrm{O} 1 \mathrm{~W}-\mathrm{H} 1 \mathrm{WB} \cdots \mathrm{O} 2 \mathrm{~A}^{\mathrm{iii}}$ & $0.85(5)$ & $2.13(4)$ & $2.973(11)$ & $172(7)$ \\
\hline $\mathrm{O} 1 \mathrm{~W}-\mathrm{H} 1 \mathrm{WB} \cdots \mathrm{O} 2 \mathrm{~B}^{\mathrm{iii}}$ & $0.85(5)$ & $2.22(6)$ & $2.985(19)$ & $151(6)$ \\
\hline $\mathrm{O} 1 \mathrm{~W}-\mathrm{H} 1 \mathrm{WB} \cdots \mathrm{O} 3 \mathrm{~A}^{\mathrm{iii}}$ & $0.85(5)$ & $2.39(7)$ & $2.998(19)$ & $129(5)$ \\
\hline $\mathrm{N} 2-\mathrm{H} 2 \mathrm{~N} \cdots \mathrm{O} 1 \mathrm{~W}$ & $0.90(3)$ & $1.86(4)$ & $2.722(5)$ & $160(4)$ \\
\hline $\mathrm{O} 2 \mathrm{~W}-\mathrm{H} 2 \mathrm{WA} \cdots \mathrm{O} 3 \mathrm{~B}^{\mathrm{iv}}$ & $0.84(3)$ & $2.31(3)$ & $3.115(16)$ & $157(4)$ \\
\hline $\mathrm{O} 2 \mathrm{~W}-\mathrm{H} 2 \mathrm{WA} \cdots \mathrm{O} 4 \mathrm{~A}^{\mathrm{iv}}$ & $0.84(3)$ & $2.01(4)$ & $2.788(11)$ & $151(6)$ \\
\hline $\mathrm{N} 15-\mathrm{H} 15 \mathrm{~N} \cdots \mathrm{O} 2 \mathrm{~W}^{\mathrm{v}}$ & $0.97(3)$ & $1.75(3)$ & $2.712(8)$ & $175(12)$ \\
\hline
\end{tabular}

Symmetry codes

(1) (i) $-x+1, y-1 / 2,-z+1 / 2$; (ii) $-x,-y,-z$

(2) (i) $x, y-1, z$; (ii) $-x+1,-y+1,-z+1$

(3) (i) $-x,-y,-z$; (ii) $-x+1, y-1 / 2,-z+1 / 2$

(4) (ii) $-x+1 / 2,-y+1 / 2, z$; (iii) $-x+1, y+1 / 2,-z+1 / 2$; (iv) $x+1 / 2,-y,-z+1 / 2 ;(\mathrm{v})-x+1,-y+1,-z$

plane and the pyridine ring being 7.81(13) and $8.94(12)^{\circ}$. In the crystal, the $\mathrm{N}-\mathrm{H} \cdots \mathrm{O}$ hydrogen bonds lead to the formation of centrosymmetric dimer-like structures decorated by $\mathrm{NO}_{3}{ }^{-}$anions (Fig. 3b; Table 3).

Crystal structure of $\left[\mathrm{Cu}(\mathrm{PBI})_{3}\right]\left(\mathrm{ClO}_{4}\right)_{2} \cdot 3 \mathrm{H}_{2} \mathrm{O}(4)$

Complex $\mathbf{4}$ is isostructural to complex $\mathbf{2}$, but crystallizes in the orthorhombic space group Pccn, and the cation possesses 2 -fold symmetry. A perspective view of the molecular structure of complex $\mathbf{4}$ is shown in Fig. 4a. The central $\mathrm{Cu}^{\mathrm{II}}$ ion is located on the 2 -fold rotation axis and is hexacoordinated by three bidentate chelating PBI ligands forming a somewhat distorted octahedron similar to the situation in complex 2 . One of the ligands is positionally disordered about the 2-fold axis, whereas the other two PBI ligands, related by the 2-fold symmetry, are normal. This type of disorder was not observed in complex 2 . The perchlorate groups are also disordered and do not coordinate to the 
Fig. 1 a A view of the molecular structure of complex 1, with displacement ellipsoids drawn at the $50 \%$ probability level. b A view along the $b$-axis of the crystal packing of complex 1. The $\mathrm{N}-\mathrm{H} \cdots \mathrm{O}$ hydrogen bonds are shown as thin black lines $[\mathrm{H}$-atoms not involved in hydrogen bonding have been removed for clarity]
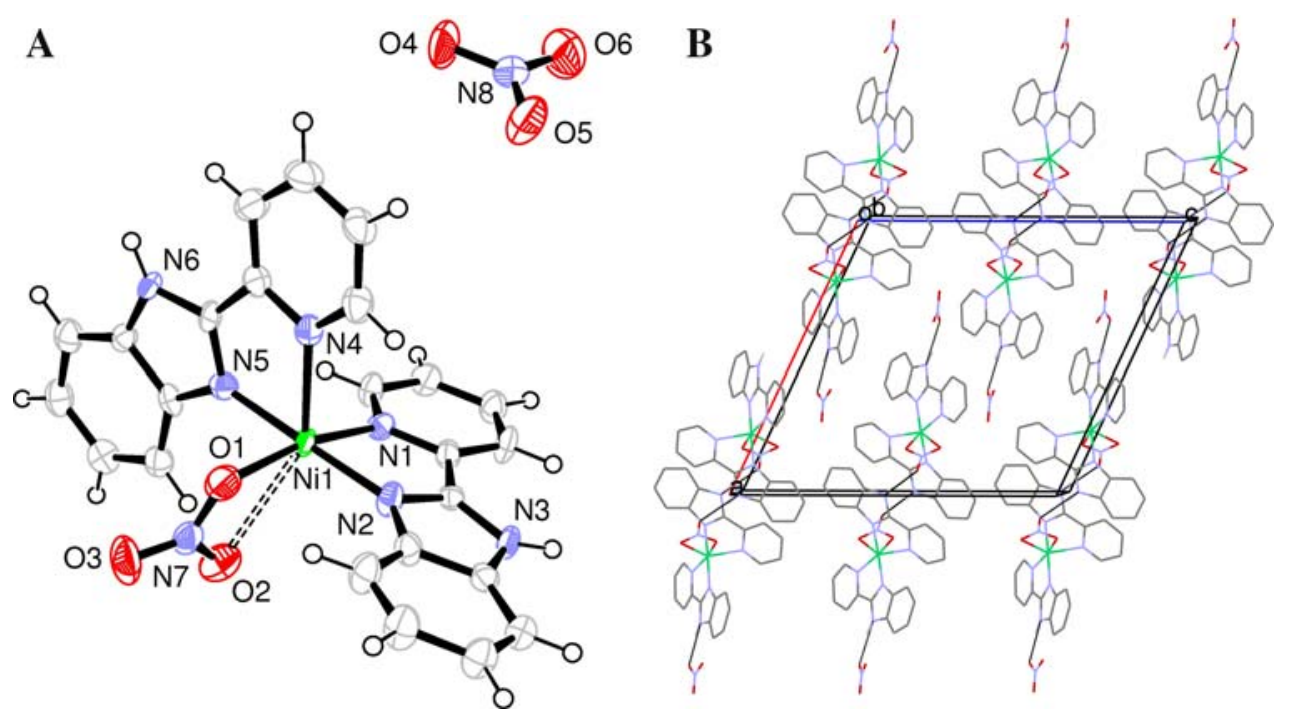

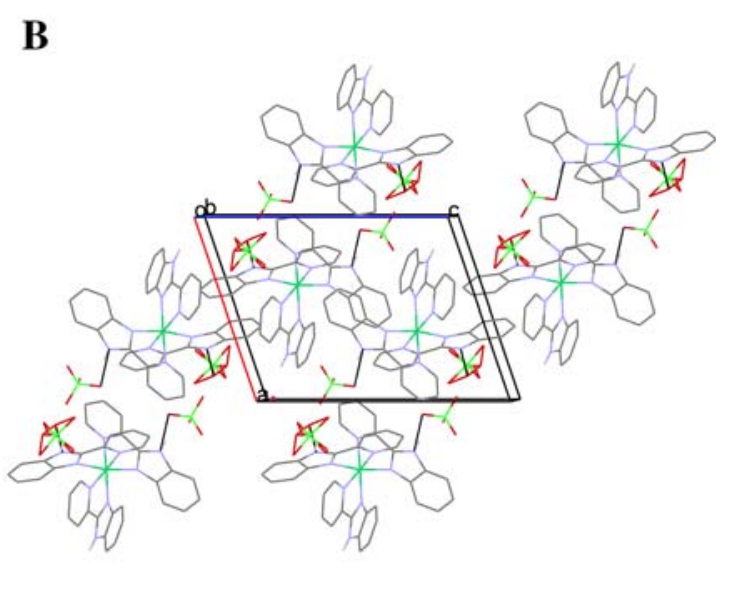

Fig. 2 a A view of the molecular structure of complex 2, with displacement ellipsoids drawn at the $50 \%$ probability level. The water molecules of crystallization and the perchlorate anions have been omitted for clarity. b A view along the $b$-axis of the crystal packing of complex 2 . The $\mathrm{N}-\mathrm{H} \cdots \mathrm{O}$ hydrogen bonds are shown as thin black lines [H-atoms not involved in hydrogen bonding have been removed for clarity]
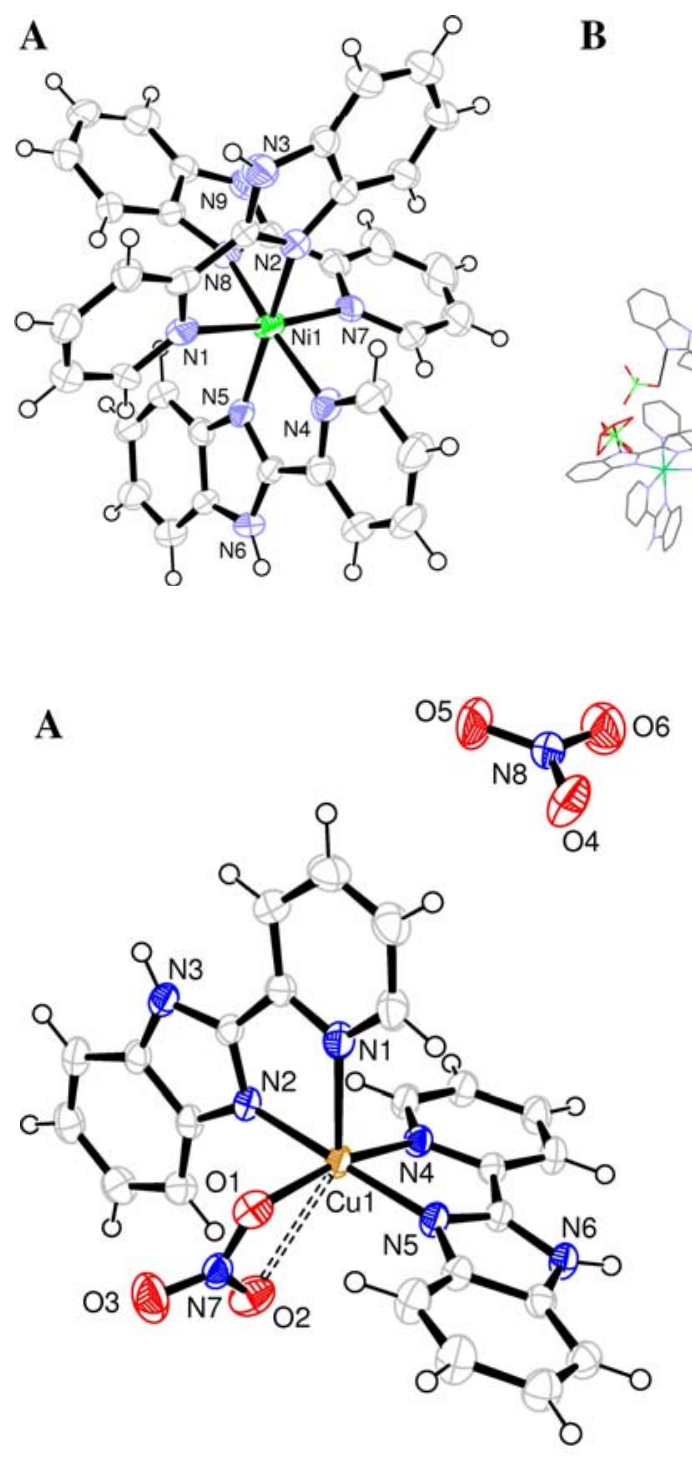

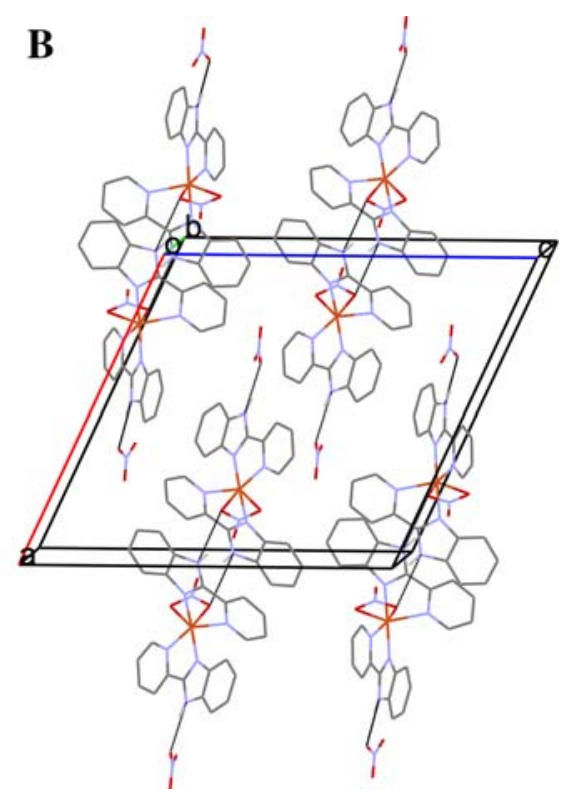

Fig. 3 a A view of the molecular structure of complex 3, with displacement ellipsoids drawn at the $50 \%$ probability level. b A view along the $b$-axis of the crystal packing of complex 3. The $\mathrm{N}-\mathrm{H} \cdots \mathrm{O}$ hydrogen bonds are shown as thin black lines $[\mathrm{H}$-atoms not involved in hydrogen bonding have been removed for clarity]

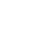




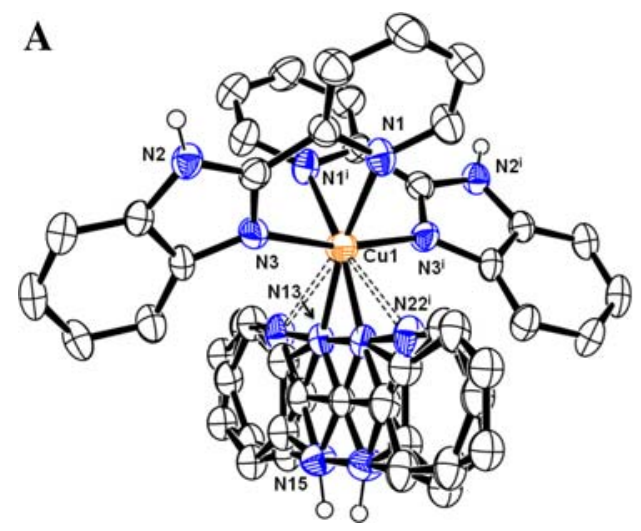

Fig. 4 a A view of the complex 4 cation, with displacement ellipsoids drawn at the $50 \%$ probability level. C-bound $\mathrm{H}$-atoms and the perchlorate anions and water molecules of crystallization have been omitted for clarity. Symmetry code: (i) $-x+1 / 2,-y+3 / 2$, $z$.

metal center. The $\mathrm{Cu}-\mathrm{N}$ bond lengths vary from $1.867(5)$ to 2.639(3) $\AA$, and the $\mathrm{N}-\mathrm{Ni}-\mathrm{N}$ bond angles range from $72.79(19)$ to $169.97(10)^{\circ}$. The bond angles and bond distances of two PBI ligands are in the normal range, while the third PBI ligand is completely disordered (Table 2). The crystal structure of complex $\mathbf{4}$ shows considerable differences with that of complex 2 . Again the pyridyl and benzimidazole mean planes of the PBI ligands are not coplanar, with dihedral angles of 8.36(10) and 7.63(17) ${ }^{\circ}$. The distortions are believed to be due to the presence of $\mathrm{N}-\mathrm{H} \cdots \mathrm{O}$ hydrogen bonding interactions (Table 3 ). The perchlorate anions and the water molecules of crystallization are involved in $\mathrm{N}-\mathrm{H} \cdots \mathrm{O}$ and $\mathrm{O}-\mathrm{H} \cdots \mathrm{O}$ hydrogen bonds bridging two symmetry-related cations, thus forming cyclic arrangements, as shown in Fig. 4b, which in turn lead to the formation of two-dimensional hydrogen-bonded networks parallel to plane (011).

\section{Spectroscopic properties}

IR spectra of the $\mathrm{Cu}^{\mathrm{II}}$ and $\mathrm{Ni}^{\mathrm{II}}$ complexes 2 and $\mathbf{4}$ show broad absorption bands centered at 3,513 and $3,550 \mathrm{~cm}^{-1}$, associated with the presence of lattice water molecules. For all four complexes and the free ligand, a stronger band in the region $3,400-3,450 \mathrm{~cm}^{-1}$ was observed for the $\mathrm{N}-\mathrm{H}$ group of the PBI ligand. Other important absorption bands for the pyridyl and imidazole $\mathrm{C}=\mathrm{N}$ groups of the free ligand are observed at 1,593 and $1,568 \mathrm{~cm}^{-1}$. In complexes $\mathbf{1 - 4}$, the same bands are displaced and observed in the range $1,600-1,620 \mathrm{~cm}^{-1}$. This shift of the absorption peaks for the pyridyl and imidazole $\mathrm{N}$-donor groups provides additional evidence for the coordination of the PBI ligand with the $\mathrm{Cu}^{\mathrm{II}}$ and $\mathrm{Ni}^{\mathrm{II}}$ ions.

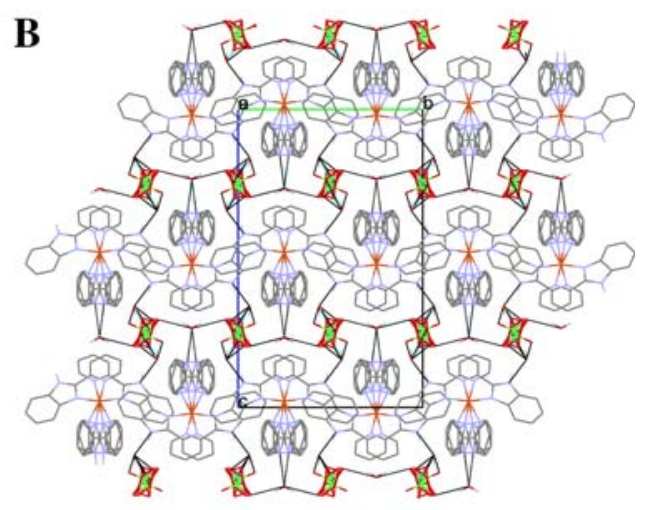

b A view along the $a$-axis of the crystal packing of complex 4. The $\mathrm{N}-\mathrm{H} \cdots \mathrm{O}$ and $\mathrm{O}-\mathrm{H} \cdots \mathrm{O}$ hydrogen bonds are shown as thin black lines [H-atoms not involved in hydrogen bonding have been removed for clarity]

\section{Conclusions}

Four new transition metal complexes of the ligand 2-(2pyridyl)benzimidazole (PBI) have been synthesized and characterized by X-ray diffraction analysis. It has been shown that under the same experimental conditions nickel(II) and copper(II) salts, with the same counter anion, can have the same coordination behavior toward the ligand 2(2-pyridyl)benzimidazole (PBI). In the nitrate complexes, 1 and $\mathbf{3}$, the metal centers are penta-coordinated while in the perchlorate complexes, $\mathbf{2}$ and $\mathbf{4}$, they are hexa-coordinated. In the crystal structures, intermolecular hydrogen bonds give rise to the formation of centrosymmetric dimer-like structures for $\mathbf{1}$ and $\mathbf{3}$, decorated by hydrogen-bonded nitrate anions. In $\mathbf{2}$ and $\mathbf{4}$, the perchlorate anions and the water molecules of crystallization are involved in $\mathrm{N}-\mathrm{H} \cdots \mathrm{O}$ and $\mathrm{O}-\mathrm{H} \cdots \mathrm{O}$ hydrogen bonds bridging two symmetryrelated cations, thus forming cyclic arrangements. In the case of complex 4, this leads to the formation of twodimensional hydrogen-bonded networks parallel to plane (011).

\section{Supplementary material}

Crystallographic data (excluding structure factors) for the structures 1-4 have been deposited with the Cambridge Crystallographic Data Centre as supplementary publication numbers CCDC 721631 (1), CCDC 721632 (2), CCDC 721633 (3), and CCDC 721634 (4). Copies of the data can be obtained free of charge on application to CCDS, 12 Union Road, Cambridge CB2 1EZ, UK [Fax: (international) +44-1223/336-033; E-mail: deposit@ccds.cam. ac.uk]. 
Acknowledgments We thank the Swiss National Science Foundation for financial support (Grant No. F20-111738).

\section{References}

1. Leko A, Gojko V (1932) Bull Soc Chim Roy Yougosl 3:85

2. Shavaleev NM, Bell ZR, Easun TL, Rutkaite R, Swanson L, Ward MD (2004) Dalton Trans 3678

3. Baran Y, Linert W (1999) J Chem Crystallogr 29:1077

4. Peng S-M, Chen H-F (1990) Bull Inst Chem Acad Sin 37:49

5. Kabanos TA, Keramidas AD, Mentzafos D, Rossu U, Terzis A, Tsangaris JM (1992) J Chem Soc, Dalton Trans 2729

6. Mock C, Puscasu I, Rauterkus MJ, Tallen G, Wolff JEA, Krebs B (2001) Inorg Chim Acta 319:109

7. Bermejo MR, Sousa A, Fondo M, Helliwell M (2000) New J Chem 24:33

8. Muller-Buschbaum K, Quitmann CC (2003) Inorg Chem 42:2742

9. Rowan R, Tallon T, Sheahan AM, Curran R, MacCann M, Kavanagh K, Devereux M, McKee V (2006) Polyhedron 25:1771

10. Munakata M, Yan S-G, Maekawa M, Akiyama M, Kitagawa S, (1997) J Chem Soc, Dalton Trans 4257

11. Haga M (1983) Inorg Chim Acta 75:29

12. Mishra D, Naskar S, Butcher RJ, Chattopadhyay SK (2005) Inorg Chim Acta 358:3115

13. Liu Q-D, Jia W-L, Wang S (2005) Inorg Chem 44:1332

14. Yue S-M, Su Z-M, Ma J-F, Liao Y, Kan Y-H, Zhanf H-J (2003) Chin J Struc Chem (Jiegou Huaxue) 22:174

15. Kaupp G (2005) Top Curr Chem 254:95-183

16. Jones RD, Summerville DA, Basolo F (1979) Chem Rev 79:139

17. Olive GH, Olive S (1984) The Chemistry of the Catalyze Hydrogenation of Carbon Monoxide. Springer, Berlin, p 152

18. Dugas H, Penney C (1981) Bioorganic Chemistry. Springer, New York, p 435
19. Mergerum JD, Miller LJ (1971) Photochromism, Interscience. Wiley, New York, p 569

20. Sancak K, Er M, ünver Y, Yildrim M, Degirmencioglu I (2007) Trans Met Chem 32:16

21. Labàdi I, Czibulya Zs, Tudose R, Costisor O (2004) J Therm Anal Calorim 78:965

22. Ghoshal D, Maji TK, Mostafa G, Sain S, Lu T.-H, Ribas J, Zangrando E, Chaudhruri NR (2004) Dalton Trans 1687

23. Eddaoudi M, Li H, Yaghi OM (2000) J Am Chem Soc 122:1391

24. Fujita M, Kwon YJ, Washizu S, Ogura K (1994) J Am Chem Soc 116:1151

25. Martin EM, Bereman RD, Dorfman J (1990) Inorg Chim Acta $176: 247$

26. Hausinger RP (1987) Microbiol Rev 51:22

27. Cammack $R$ (1988) Adv Inorg Chem 32:297

28. McCormick T, Jia W-L, Wang S (2006) Inorg Chem 45:147

29. Kaes C, katz A, Hosseini MW (2000) Chem Rev 100:3553

30. Vogler A, Kunkely H (1998) Coord Chem Rev 177:81

31. Grätzel M (2004) J Photochem Photobiol A: Chem 164:3

32. Rudmann H, Shimada S, Rubner MF (2002) J Am Chem Soc $124: 4918$

33. Likhanova NV, Veloz MA, Hopti H, Matias DJ, Reyes-Cruz VE, Olivares O, Martinez-Palou R (2007) J Hetrocycl Chem 44:145

34. Stoe (2000) IPDS-I Bedienungshandbuch. Stoe \& Cie GmbH, Darmstadt, Germany

35. Stoe (2006) X-Area V1.35 and X-RED32 V1.31 Software. Stoe \& Cie GmbH, Darmstadt, Germany

36. Sheldrick GM (2008) Acta Crystallogr A64:112

37. Blessing RH (1995) Acta Crystallogr A51:33

38. Spek AL (2009) Acta Crystallogr D65:148

39. Addison AW, Rao TW, Reedijk J, van Rijn J, Verschoor GC (1984) J Chem Soc, Dalton Trans 1349

40. Boca R, Boca M, Ehrenberg H, Fuess H, Linert W, Renz F, Svoboda I (2003) Chem Phys 293:375 